\title{
A Filosofia na Formação de Professores de Química em Minas Gerais: $O$ que se Mostra nos Componentes Curriculares de Licenciaturas em Química?
}

\section{Philosophy In Teachers' Education In Minas Gerais State: What Is Shown In Curricular Components Of Chemistry Undergraduate}

\section{Courses?}

\section{Robson S. de Sousa, Alexandre R. dos Santos e Maria do Carmo Galiazzi}

\begin{abstract}
Resumo: Neste artigo, apresentamos percepções e elaboramos compreensões acerca da formação filosófica de professores de Química. Fundamentamos nossa investigação em uma proposição de uma Filosofia da Educação em Ciências - que articula a Filosofia, a Filosofia da Educação e a Filosofia da Ciência como eixos formadores dos estudos neste campo. Identificamos componentes curriculares nesses eixos nos cursos de Licenciatura em Química das Universidades Federais do Estado de Minas Gerais. As ementas desses componentes curriculares foram analisadas com a pergunta fenomenológica de pesquisa : "O que é isto que se mostra: a Filosofia na formação de professores de Química em Minas Gerais?”. Dos 23 cursos de Licenciatura em Química encontrados, 10 deles possuem vínculo com a Filosofia no nome do componente curricular. Nestes cursos, foram identificados 13 componentes curriculares com este vínculo, majoritariamente atribuídos à Filosofia da Educação. Na análise realizada, emerge a ideia de uma formação filosófica de professores de Química vinculada a aspectos epistemológicos, metodológicos e curriculares do conhecimento científico.
\end{abstract}

Palavras-chave: Filosofia da Educação em Ciências. Educação Química. Formação de Professores. Filosofia da Educação. Filosofia da Ciência.

\begin{abstract}
In this article, we present perceptions and elaborate understandings about the philosophical education of chemistry teachers. Our investigation is based on a proposal of a Philosophy of Science Education - which articulates Philosophy, Philosophy of Education and Philosophy of Science as formative axes of studies in this field. Curricular components belonging to these axes were identified in undergraduate courses in Chemistry of Federal Universities of the State of Minas Gerais. The available syllabuses were analyzed from the phenomenological question: "What is philosophy in chemistry teachers' education?". Of the 23 undergraduate courses in Chemistry found, only 10 entail philosophy in the name of curricular components. Of these, 13 curricular components with this link were identified, mainly attributed to the Philosophy of Education or the Foundations of Education. In the analysis carried out, it emerges the idea of a philosophical education of Chemistry teachers linked to epistemological, methodological and curricular aspects of scientific knowledge.
\end{abstract}

Keywords: Philosophy of Science Education. Chemistry Education. Teachers Education. Philosophy of Education. Philosophy of Science.

\footnotetext{
Robson Simplicio de Sousa (robsonsimplicio@ @otmail.com) é doutor em Educação em Ciências pela Universidade Federal do Rio Grande (FURG), mestre em Química Tecnológica e Ambiental pela FURG e licenciado em Química pela Universidade Federal de Pelotas (UFPel). Atua como professor adjunto no Departamento de Sociais e Humanas da Universidade Federal do Paraná (UFPR), Setor Palotina. Palotina, PR - BR. Alexandre Rodrigues dos Santos (santos.18alexandre@ gmail.com) é acadêmico do curso de Licenciatura em Química da Universidade Federal do Triângulo Mineiro (UFTM). Iturama, MG - BR. Maria do Carmo Galiazzi (mcgaliazzi@gmail.com) é doutora e mestre em Educação pela Pontifícia Universidade Católica do Rio Grande do Sul (PUCRS), licenciada em Química pela FURG e bacharel em Química pela Universidade Federal do Rio Grande do Sul (UFRGS). É professora titular voluntária na FURG. Rio Grande, RS - BR. Recebido em 21/11/2018, aceito em 17/12/2018
}

A seção "Cadernos de Pesquisa" é um espaço dedicado exclusivamente para artigos inéditos (empíricos, de revisão ou teóricos) que apresentem profundidade teórico-metodológica, gerem conhecimentos novos para a área e contribuições para o avanço da pesquisa em Ensino de Química. 
A construção da identidade de um professor de Ciências se vincula aos aspectos filosóficos por ele apropriados, uma vez que é a partir deles que o professor expõe suas concepções epistemológicas, a ciência que ensina e aprende, o modo como a propaga e sua disposição às relações educativas (Schulz, 2014). Isto repercute no modo como o professor escolhe conteúdos de ensino, como planeja esse ensino e como se compromete com a formação do estudante e com a sua própria formação, à medida que questiona sua prática. Assim, neste artigo, questionamonos sobre como se apresentam os aspectos filosóficos na formação acadêmica de professores de Química. Buscamos, a partir desse questionamento, delinear pressupostos filosóficos que se mostram nas ementas dos currículos de formação universitária de estudantes de cursos de Licenciatura em Química em Minas Gerais.

Nosso interesse teórico parte de Schulz (2014), quando afirma que muito do afastamento dos professores de Ciências em relação à Filosofia é responsabilidade da própria academia que o forma. Isto se constitui no que o autor chama de uma insuficiência filo-educacional que desemboca numa maior vinculação do professor de Ciências à ciência, em função do prestígio atribuído ao cientista, em detrimento da Educação em Ciências e seus aspectos filosóficos. Trataremos, neste artigo, especificamente, do que se mostra nas ementas acerca desses aspectos filosóficos, cuja vinculação inquestionável ao paradigma que norteia a construção da ciência que ensina, desdobra-se em uma problemática para a Educação Química.

A construção da Química está fundamentada em uma racionalidade técnico-científica que sustenta a ciência calcada no positivismo como modo de conhecer o mundo. Referimo-nos ao modo de olhar o mundo que se centra em discriminar, classificar e identificar as coisas com padrões previamente estabelecidos, buscando dominá-las. Constrói-se baseada numa linguagem de medida e aferição com o propósito de computar novas ideias, hipóteses com vistas à produção de novos produtos de interesse do mercado. Aposta fortemente na competitividade, com foco em um desenvolvimento cujo projeto presente é melhor do que o anterior. Seus conhecimentos são baseados em verificações corretas, pois foram elaborados por métodos que permitem a eliminação do erro (Martins e Bicudo, 2006). Em um contexto educativo, vincular-se exclusivamente a uma racionalidade técnico-científica reduz possibilidades formativas do Educar Quimicamente. Isto porque

O ideal de cientificidade herdado do Iluminismo impõe uma orientação objetificadora e tecnificada ao processo educativo contrária à multiplicidade de concepções e ideais que irrompem da diversidade biográfica e da multiplicidade cultural. Regras, normas e esquemas burocráticos traduzidos na rigidez e no esquematismo disciplinar predeterminado segmentam a ação educativa destituindo-a da autonomia, conectividade e autorreflexividade indispensáveis ao processo formativo (Flickinger, 2010, p. XVIII-XIX).

O ensino de Química tem sido tratado com objetivismo ${ }^{1}$ (Sjöström, 2007), com pouco diálogo entre os sujeitos envolvidos no processo educativo, raro tratamento das tradições históricas ${ }^{2}$ e estéticas da Química e de seu ensino, além do escasso registro por meio da escrita das compreensões alcançadas, enquanto materialidade do ato educativo (Sousa e Galiazzi, 2017; 2018). A sala de aula de Química tem sido caracterizada como a ciência, um lugar de domínio e de controle da razão.

A moderna educação de professores em Ciências tem passado à margem da Filosofia e da Filosofia da Educação em favorecimento de estudos em Psicologia e ciências cognitivas, especialmente, em teorias de aprendizagem e de desenvolvimento (Schulz, 2014). Entretanto, se considerarmos que a educação significa mais do que o uso de técnicas instrucionais e que abrange intenções amplas, incluindo uma educação cidadã e questões fundacionais sobre a natureza da educação, da aprendizagem, do conhecimento e da ciência, então a Filosofia precisa ser trazida à baila (Schulz, 2014) e ser cada vez mais incluída nos cursos de Licenciatura em Química.

Para Röhr (2015), existem muitas teorias educacionais disponíveis à escolha do educador que podem guiar suas práticas educativas. Aquele que toma para si a responsabilidade de escolher uma teoria a seguir pode: i. compreender a educação como aquela em que a tarefa pedagógica se reduz a algo que pode ser plenamente realizado; ou ii. questionar-se acerca das consequências negativas de visões mais restritas da educação e também das contribuições positivas daquelas mais amplas, nas quais se incluem as facetas da vida humana. Na primeira escolha, pouco interessam os fundamentos filosóficos orientadores da prática docente, pois a tarefa pedagógica está pronta, é preciso apenas aplicá-la. A segunda escolha, uma aposta no questionamento e na reflexão, exige do professor conhecer, escolher e se posicionar diante de fundamentos filosóficos para poder avaliar sua prática educativa.

Diante disso, buscamos elaborar compreensões a partir da análise de ementas que compõem o currículo em cursos de Licenciatura em Química. Utilizamo-nos da hermenêutica como suporte teórico para a compreensão filosófica do currículo, como nos traz Berticelli (2010) ao afirmar que

O currículo é sempre proposta de experiência do mundo. Por outro lado, ele é experiência do mundo. É um tipo de experiência proposto aos educandos. $O$ currículo é sempre uma complexa trama de mundos vividos e não de um só mundo, pois ele resulta de muitas experiências históricas e de projeto para ofuturo de muitas histórias: as histórias dos educandos junto com as histórias dos educadores, no sentido mais amplo de compreensão possível. Assim, me 
autorizo a dizer que o currículo é uma trama tecida de linguagens (Berticelli, 2010, p. 73).

Com isso, o currículo se materializa na linguagem. É, portanto, um texto, um discurso que se constitui no pensamento educacional, nas normas, nas intenções, na filosofia, na ideologia, nos conteúdos de ciência e o que mais que possa estar nele incluído (Berticelli, 2010). A partir de sua natureza linguística, compreendê-lo significa interpretá-lo. Esta é nossa intenção com o presente artigo.

Como apresentamos acima, compreendemos o currículo além de "matrizes" e "grades" curriculares, além dos projetos políticos pedagógicos e além das ementas que o compõem. Entretanto, nosso esforço analítico foi o de compreender a partir dos textos que estes currículos nos disponibilizaram, as ementas, entendendo-os sempre como intencionalidades do real, sempre parciais e incompletos ao descreverem a prática curricular.

Nesta interpretação de textos, somos influenciados pela Fenomenologia, uma postura filosófica com uma visão de conhecimento e realidade na qual sujeito e objeto não são separados, mas estão ontologicamente unidos (Martins e Bicudo, 2006). É a busca de "dirigir-se para o fenômeno da experiência, para o dado, e procurar vê-lo da forma como ele se mostra na própria experiência em que é percebido" (Martins e Bicudo, 2006, p. 16). Nosso modo de perguntar nesta investigação é de estranhamento, é de dar-se conta do percebido e de espantar-se com o que percebemos. Assim, na Fenomenologia, perguntamos "o que é isto?" para ressaltar este dar-se conta de que percebeu o que lhe estranha, tanto que se torna um fenômeno a ser investigado. Neste artigo, questionamos $\boldsymbol{O}$ que é isto que se mostra: a Filosofia na formação de professores de Química em Minas Gerais?

Restringimos nossa análise a cursos de Licenciatura em Química de Universidades Federais do Estado de Minas Gerais. Isto se justifica em função de que Minas Gerais é o Estado da federação com mais universidades federais.

Orientamos nossa investigação a partir do que Schulz (2014) chama de Filosofia da Educação em Ciências, o que será apresentado na segunda seção deste artigo. Na terceira seção, identificamos e mapeamos, utilizando o software Qgis, ${ }^{3}$ os cursos de Licenciatura em Química com componentes curriculares de interesse - Filosofia, Filosofia da Educação e Filosofia da Ciência. Na quarta seção, utilizamo-nos da Análise Textual Discursiva (ATD) para a análise dos textos das ementas desses componentes curriculares. ${ }^{4}$ A Análise Textual Discursiva (Moraes e Galiazzi, 2016; Sousa et al., 2016; Sousa e Galiazzi, 2016) assume os princípios fenomenológicos e hermenêuticos, exigindo a descrição detalhada do fenômeno para perceber como este se mostra. Nesse caminho, o exercício foi feito a partir dos significados das palavras intencionalmente escolhidas, permitindo movimentar-nos baseados em preconceitos com vistas a horizontes de compreensão ampliados para a construção do metatexto.

A ATD realizada partiu das ementas dos componentes curriculares de interesse, o corpus de análise. As ementas são constituídas, basicamente, de títulos de conteúdos a serem trabalhados nos componentes curriculares. Ao fragmentarmos este corpus, foi necessária a reescrita das unidades de significado, conforme dos orienta a metodologia de análise:

(...) como na fragmentação sempre se tende a descontextualizar as ideias, é importante reescrever as unidades de modo que expressem com clareza os sentidos construídos a partir do contexto de sua produção. Isso implica incluir alguns elementos de unidades anteriores ou posteriores dentro da sequência do texto original. Isso se faz necessário, pois as unidades, quando levadas à categorização, estarão isoladas e é importante que seu sentido seja claro e fiel às vozes dos sujeitos da pesquisa (Moraes e Galiazzi, 2016, p. 41-42).

Assim, trabalhamos na análise com as unidades de significados reescritas com seus sentidos os mais completos possível, para que delas pudéssemos seguir para a categorização. A aproximação realizada foi a partir de categorias a priori que são explicitadas na seção dois (Tabela 1).

Na categorização inicial, as aproximações das unidades de significado nos levaram à elaboração de sínteses descritivas que possibilitam iniciar a construção do argumento em torno da categoria.

Tabela 1: Exemplo do processo de unitarização realizado nas ementas

\begin{tabular}{lcll}
\hline Universidade & Componente Curricular & Ementa & Unidades de Significado \\
\hline UFLA Lavras & Filosofia da Educação & Estudo de diversas correntes & UFLA.1.1. Estudo de correntes filosóficas que pos- \\
& $\begin{array}{l}\text { filosóficas que possibilitem a com- } \\
\text { preensão e a intervenção crítica }\end{array}$ & $\begin{array}{l}\text { UFLA.1.2. Estudo de correntes filosóficas que } \\
\text { e reflexiva no processo educativo. }\end{array}$ & $\begin{array}{l}\text { possibilitem a intervenção crítica no processo } \\
\text { educativo. } \\
\end{array}$ \\
& & $\begin{array}{l}\text { UFLA.1.3. Estudo de correntes filosóficas que } \\
\text { possibilitem a intervenção reflexiva no processo } \\
\end{array}$ \\
& & educativo. \\
\hline
\end{tabular}


Os sistemas de categorias correspondem a sínteses dos elementos que mais se destacam nos fenômenos investigados. Nesse sentido, constituem pontes para a realização de inferências dos textos aos contextos, dos materiais analisados para os fenômenos pesquisados. A concretização, cada vez. mais elaborada, dessas inferências, aparecerá em forma de meta-textos descritivos e interpretativos, expressando as compreensões atingidas (Moraes e Galiazzi, 2016, p. 112).

Em um processo recursivo de aproximação, as categorias finais apresentam-se com um parágrafo-síntese (Tabela 2) que abre o metatexto de cada uma delas como mostrado na seção quatro.

O parágrafo-síntese orienta a percepção do investigador que busca fenomenologicamente escutar as palavras que dele emergem. Sobre isso, Sousa e Galiazzi (2016, p. 50) afirmam que "Na ATD o sentido dado à palavra emergência é aquele da compreensão que surge durante o processo de análise que o pesquisador, como sujeito histórico, percebe, o que o leva a uma teoria antes não reconhecida, mas parte de suas précompreensões." Essas palavras orientam o processo descritivo e interpretativo do metatexto, articulando-o com teóricos para a construção de argumentos na categoria em análise. ${ }^{5}$

Por fim, na quinta seção, apresentamos as considerações finais deste artigo.

\section{Sobre Uma Filosofia da Educação em Ciências}

Schulz (2014) defende que a Educação em Ciências, tanto como investigação acadêmica quanto como campo de prática, requer internamente o desenvolvimento de uma filosofia, de modo a realizar suas mudanças como uma disciplina de pesquisa e de profissão. Para o autor, a Educação em Ciências se mostra pouco disposta a tratar de suas questões filosóficas. Muitos pesquisadores e professores estão mais interessados em aplicações práticas imediatas, porque a área tem sido associada ao treinamento de técnicas de ensino e de aprendizagem, com foco nas teorias fundamentadas na Psicologia.

Muitas das preocupações e dos questionamentos da comunidade de Educação em Ciências são intrinsecamente filosóficas e perpassam a Filosofia da Educação e a Filosofia da Ciência. É por isso que, no livro Rethinking Science Education: Philosophical Perspectives, Schulz (2014) reivindica a posição, segundo ele ainda bastante negligenciada, da Filosofia na/da Educação em Ciências. Há, portanto,

a necessidade de reexaminar e de repensar os problemas comuns do terreno científico educacional - associados com os objetivos (especialmente de alfabetização ou letramento científico), currículo, questões de aprendizagem, natureza da ciência e linguagem - a partir de perspectivas filosóficas estimulantes, com a intenção de prover soluções oferecendo novas ideias, novos caminhos de pesquisa (Schulz, 2014, p. 17).

O autor fundamentou uma Filosofia da Educação em Ciências (FEC) estruturada pela intersecção ou integração de três campos acadêmicos: Filosofia, Filosofia da Educação e Filosofia/História da Ciência (Figura 1). A organização gráfica apresentada possibilita a professores e pesquisadores uma estrutura holística para vincularem suas análises específicas.

Em sua construção em direção a uma FEC, Schulz argumenta que as questões filosóficas envolvendo tanto a educação quanto a ciência estão no centro da Educação em Ciências, uma vez que o papel profissional do professor tem sido cocriar, orientar e avaliar os documentos oficiais de ensino de Ciências, pois essas tarefas requerem a mistura de aspectos da Filosofia da Educação e da Filosofia da Ciência. A intenção é aperfeiçoar a Educação em Ciências como um campo de pesquisa e ajudar professores a ampliarem suas estruturas teóricas e melhorarem suas práticas (Schulz, 2014).

Gois (2017) aponta a importância de uma aproximação entre a Filosofia e o ensino de Ciências, e ressalta que esta aproximação possibilita melhor compreensão de elementos fronteiriços nestas duas áreas. Assim, o autor nomeia esta fronteira de Filosofia do Ensino de Ciências, segundo ele "um campo que ainda não existe, nem mesmo como linha de pesquisa de uma área" (Gois, 2017, p. 24). O autor complementa que uma Filosofia do Ensino de Ciências ${ }^{6}$ nos auxilia, enquanto comunidade de Educação em Ciências, a delimitar de modo mais seguro os pressupostos filosóficos orientadores das metodologias e dos objetivos de pesquisa.

Tabela 2: Exemplo do processo de categorização intermediária e elaboração de parágrafo-síntese

\begin{tabular}{lll}
\hline \multicolumn{1}{c}{ Categorização Intermediária } & Unidades de Significado & \multicolumn{1}{c}{ Parágrafo-síntese } \\
\hline A - A compreensão do processo educativo; & UFLA.1.1.; UFOP.1.4.; UFOP.1.5.; UNIFAL.1.2. & A Filosofia da Educação visa compreender o \\
A - A organização do currículo escolar faz parte & processo educativo, desde os saberes neces- \\
dos estudos filosóficos sobre educação; & sários à prática docente até a organização do \\
A - Os saberes necessários à prática docente & currículo escolar. \\
fazem parte dos estudos filosóficos sobre & \\
educação & \\
\hline
\end{tabular}




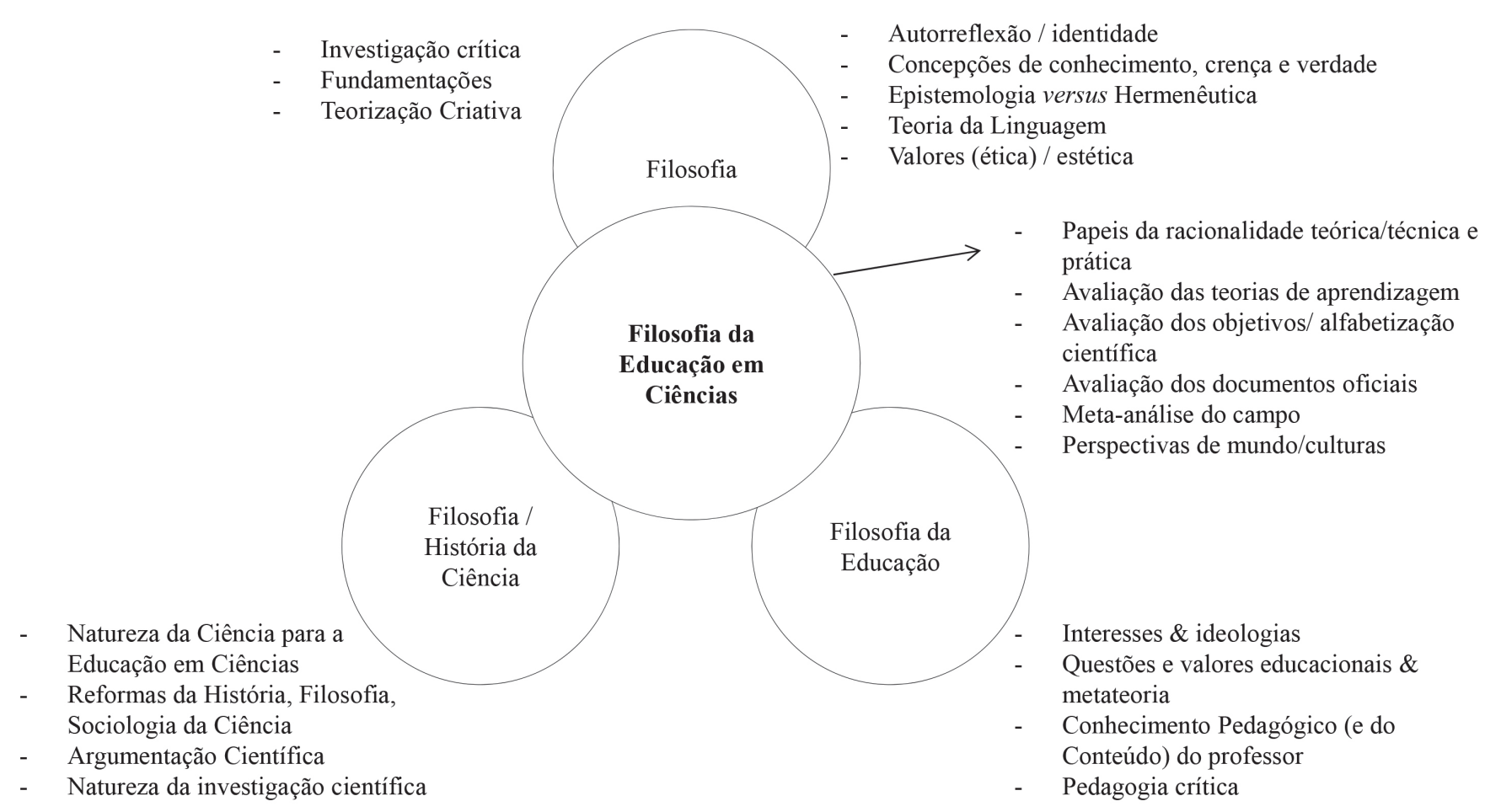

Figura 1: Estrutura da Filosofia da Educação em Ciências. Traduzido e adaptado de Schulz (2014, p. 13).

Schulz (2014) aposta que a Filosofia da Educação em Ciências possa servir como um fórum acadêmico de debate acerca dos objetivos fundamentais, dos critérios de seleção de conteúdo e de críticas às epistemologias dos métodos de pesqui$\mathrm{sa}$, das teorias de aprendizagem e das estratégias instrucionais na Educação em Ciências. Também deve ajudar a esclarecer a relação entre as teorias educacionais e a própria Filosofia, que tem suas próprias preocupações. Dentro do escopo da Filosofia da Educação em Ciências, o autor destaca:

i. objetivos da educação em ciências; ii. desenvolvimento/análise de metateorias educacionais para a educação em ciências; iii. a natureza da ciência adequada para a educação em ciências; $i v$. a aprendizagem da natureza da ciência (a crítica a teorias de aprendizagem); v. ensino e avaliação da natureza da ciência; vi. a ideologia da natureza e o interesse no currículo; critério para seleção de conteúdos; vii. natureza da linguagem no currículo, ensino e aprendizagem; viii. a relação da alfabetização científica e os objetivos da educação para as questões sócio-tecnológicas; e ix. a relação da ciência e da educação em ciências às visões de mundo e às culturas (Schulz, 2014, p. 52).

Schulz $(2010 ; 2014)$ reconhece, antes mesmo de Gois (2017), que esses tópicos não têm sido abordados na formação de profissionais da Educação em Ciências. Seu aparecimento é esporádico e disperso em periódicos científicos e livros.

Pela ausência de uma organização acadêmica em torno da
Filosofia da Educação em Ciências apontada por estes autores, neste artigo, baseamo-nos nos componentes curriculares que a integram - Filosofia, Filosofia da Educação e Filosofia da Ciência. Buscamos compreender melhor a formação filosófica em cursos de Licenciatura em Química e a integração entre esses componentes curriculares. Esse esforço teórico constitui, portanto, um exercício de identificar, descrever e interpretar textos que repercutem na formação filosófica de professores de Química, como faremos a seguir.

\section{Mapeamento de Componentes Curriculares Vinculados à Filosofia em Cursos de Licenciatura em Química em Minas Gerais}

Minas Gerais é o Estado brasileiro que possui o maior número de universidades públicas. ${ }^{7}$ São onze Universidades Federais no Estado de Minas Gerais, totalizando trinta campi universitários espalhados em diversos municípios no território mineiro. Todas as universidades federais de Minas Gerais possuem cursos de formação de professores de Química, nomeados de "Licenciatura em Química" ou "Química Licenciatura". A oferta de cursos de formação de professores de Química são nas modalidades presencial ou à distância, em 23 campi.

As datas de implantação dos Projetos Políticos Pedagógicos (PPP) - também chamados de Projetos Pedagógicos de Curso (PPC) - variam de 2008, na UNIFAL de Alfenas, a 2016, na UFV de Viçosa. Muitos dos cursos identificados não possuem seus PPC's disponíveis em seus sítios eletrônicos institucionais. ${ }^{8}$

Os componentes curriculares de nosso interesse foram aqueles que tinham explicitamente em seus nomes a palavra 
"filosofia", "filosófico", "filosófica" e seus respectivos plurais quando identificadas em suas grades curriculares, PPC's ou sítios eletrônicos das UF's de Minas Gerais. A esses componentes curriculares de interesse adicionamos aqueles cujo títulos teria alguma vinculação com "Fundamentos da Educação". Isto porque, com a cientificização da Pedagogia a partir do século XVIII, o campo da educação englobou algumas áreas das ciências humanas, tais como a História, a Psicologia, a Sociologia e a Filosofia na ampla designação de fundamentos da educação (Hermann, 2015). Isso repercutiu tanto nos cursos de Pedagogia quanto nas Licenciaturas no Brasil, nos quais se considera a Filosofia da Educação uma disciplina da área de "fundamentos da educação" (Gallo, 2007). Assim, incluímos esse componente curricular na análise.

Apenas dez dos vinte e três cursos de formação de professores de Química, distribuídos em sete UF's de Minas Gerais, ofertam componentes curriculares de Filosofia, Filosofia da Ciência, Filosofia da Educação ou Fundamentos da Educação, em treze componentes curriculares com esses critérios, conforme mostra a Figura 2.
Na Tabela 3, agrupamos os componentes curriculares de acordo com os eixos da Filosofia da Educação em Ciências. São dois em Filosofia, sete em Filosofia da Educação e dois em Filosofia da Ciência.

Outros dois componentes curriculares estão nomeados como "Aspectos Filosóficos e Sócio-Antropológicos" e "Filosofia e Metodologia das Ciências" dos cursos de Química Licenciatura da UFVJM de Diamantina e da UNIFAL de Alfenas, respectivamente. Eles não se vinculam diretamente aos eixos da FEC, mas se posicionam na interface deles.

Dos três campos de nossa investigação, destaca-se a Filosofia da Educação. Após a identificação dos componentes curriculares, percebe-se que, quantitativamente, os cursos de Licenciatura das Universidades Federais em Minas Gerais dão pouca ênfase aos aspectos filosóficos, uma vez que apenas em dez dos vinte e três cursos foram encontrados componentes curriculares com os critérios estabelecidos. Esses componentes curriculares enfatizam a Filosofia da Educação em detrimento da Filosofia da Ciência e da Filosofia em geral.

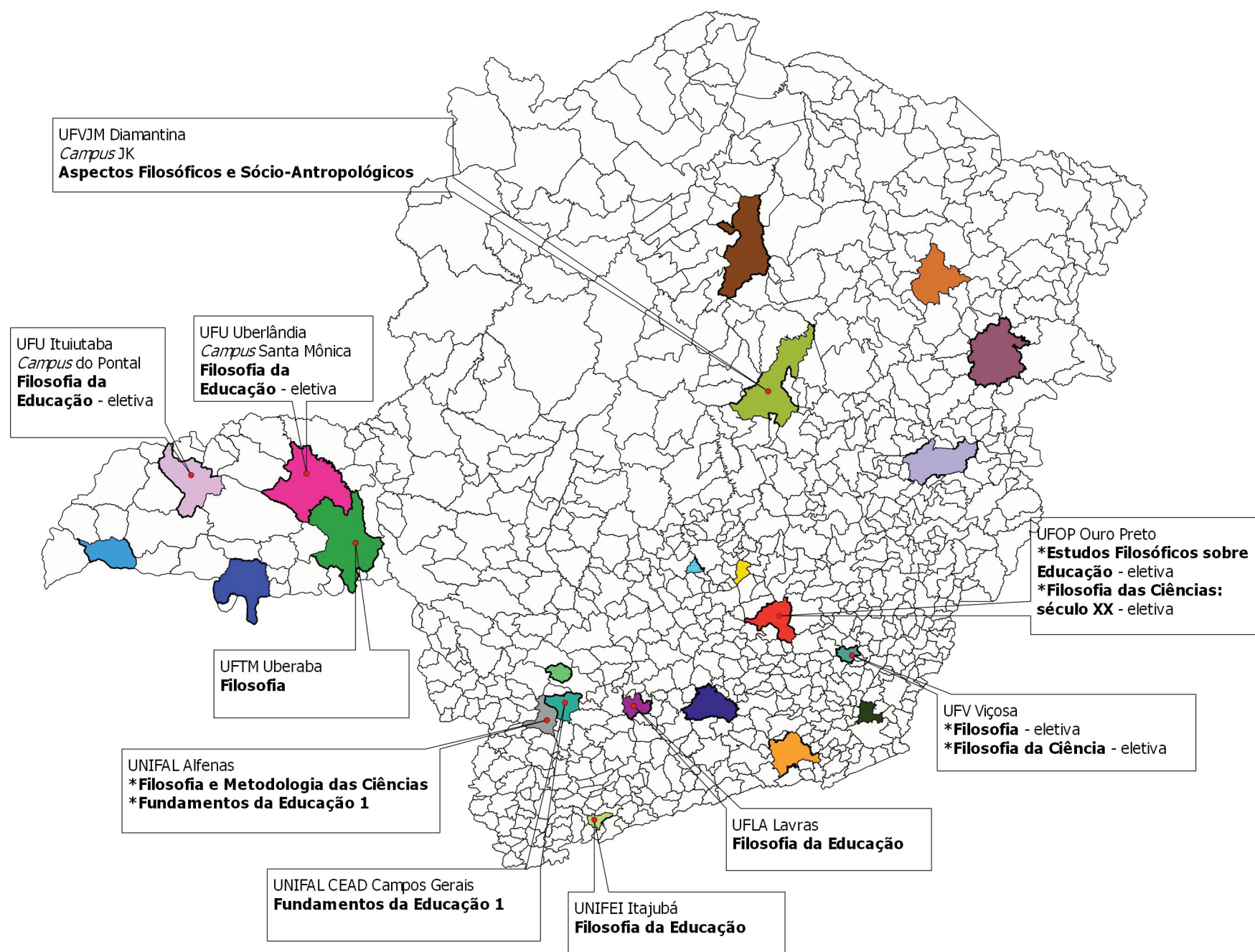

Figura 2: Identificação dos componentes curriculares em Filosofia, Filosofia da Educação, Filosofia da Ciência ou Fundamentos da Educação nos cursos de Licenciatura em Química dos Campi Universitários Federais em Minas Gerais em 2017. 
Tabela 3: Componentes curriculares nos eixos da Filosofia da Educação em Ciências identificados nos cursos de Licenciatura em Química de UF's de Minas Gerais em 2017

\begin{tabular}{lcc}
\hline Eixos da FEC & Componente Curricular & Universidade \\
\hline Filosofia & Filosofia & UFTM - Uberaba \\
& Filosofia & UFV - Viçosa \\
\hline & Filosofia da Educação - Uberlândia & UFU - Ituiutaba \\
& Filosofia da Educação & UNIFEI - Itajubá \\
Filosofia da Educação & Filosofia da Educação & UFLA - Lavras \\
& Filosofia da Educação & UNIFAL - Alfenas \\
& Fundamentos de Educação & UNIFAL - Campos Gerais \\
& Fundamentos de Educação & UFOP - Ouro Preto \\
Filosofia da Ciência & Estudos Filosóficos sobre Educação & UFV - Viçosa \\
\end{tabular}

\section{Uma Análise a Partir dos Eixos da Filosofia da Educação em Ciências na Formação de Professores de Química}

Nesta seção, apresentamos o metatexto produzido a partir da análise das ementas dos componentes curriculares vinculados à Filosofia nas Licenciaturas em Química de universidades federais em Minas Gerais por meio da Análise Textual Discursiva (Moraes e Galiazzi, 2016). Utilizamo-nos de categorias a priori, provenientes dos eixos que compõem a Filosofia da Educação em Ciências, a saber: Filosofia, Filosofia da Ciência e Filosofia da Educação (Schulz, 2014). Elas nos fizeram perceber emergências teóricas textualizadas a seguir.

\section{A Filosofia na Formação de Professores de Química: A Vinculação à Metodologia Científica como modo de Compreender o Homem e a Sociedade}

Da análise sobre a ocorrência das expressões filosofia e filosófico(a) nas ementas dos componentes curriculares foi possível elaborarmos a síntese descritiva apresentada a seguir: A Filosofia nos componentes curriculares analisados apresenta pressupostos que permitem questionar a produção do homem, seus aspectos sociais e culturais, objetivando compreender e explicar as estruturas da sociedade ao estudar historicamente a sociologia e a antropologia. Além disso, a Filosofia nos componentes curriculares analisados se mostrou vinculada à epistemologia e à metodologia das ciências nos diferentes tipos de projetos de pesquisa, aproximando-se também de métodos científicos. A Filosofia que se mostra examina as Ciências e contribui para o desenvolvimento de suas estruturas teóricas, preocupada em estudar a metodologia científica, uma vez que é por meio de tal metodologia que as descobertas das Ciências são estruturadas, teorizadas e disseminadas na academia e, posteriormente, na sociedade.

A formação universitária do professor de Química com os componentes curriculares vinculados à Filosofia busca se afastar do que Severino (2006, p. 91) chama de uma educação superior "como apenas um aparelhamento técnico para o exercício de operações funcionais na sofisticada engrenagem tecnológica da produção". Tratar a Filosofia em cursos de formação de professores de Química é colocar-se na contracorrente. Muitos gestores e teóricos da educação superior compreendem a modernização da universidade alicerçada na transmissão de uma preparação técnico-operacional para inserção na cadeia de produção (Severino, 2006).

Da análise realizada, mostrou-se que a Filosofia nos cursos de Licenciatura analisados tem se dedicado a estudar a origem das Ciências, com ênfase em sua própria história, bem como na origem histórica da Sociologia e da Antropologia (UNIFAL.1.3. A filosofia vinculada à metodologia das ciências trata da história da ciência; UFVJM.1.2. A filosofia com um tratamento sócio-antropológico aborda a origem da filosofia; UFVJM.1.3. A filosofia com um tratamento sócio-antropológico aborda a origem histórica das ciências; UFVJM.1.4. A filosofia com um tratamento sócio-antropológico aborda a origem histórica da antropologia; UFVJM.1.5. A filosofia com um tratamento sócio-antropológico aborda a origem histórica da sociologia.).

Algumas unidades de significado mostraram que, ao estudar a origem histórica das Ciências, a Filosofia encontra conjecturas que lhe permitem questionar a produção do homem em suas concepções sociais e culturais (UFV.1.1. A filosofia trata da produção do homem; UFTM.1.2. A filosofia aborda dimensões humanas; UFTM.1.3. A filosofia trata da cultura humana; UFTM.1.4. A filosofia trata da natureza humana). A Filosofia busca entender as estruturas da sociedade questionando a natureza humana, sua produção, sua cultura e seus relacionamentos sociais.

Ao levarmos em conta que a Filosofia trata do desenvolvimento do homem e da sociedade, torna-se indispensável a inserção de elementos filosóficos nos cursos universitários, não só nas licenciaturas, mas em todas as esferas da formação social e profissional. As instituições de ensino superior precisam se 
preocupar com a formação filosófica dos estudantes de todas as áreas, pois a formação filosófica retoma aspectos e dimensões estruturantes relacionadas com as tradições históricas, que servem como mediação fundamental para sua existência, seja com o conhecimento ou com o seu próprio existir histórico. Ao defender a ideia de que a natureza dessa formação é necessária ao perfil de qualquer profissional, independentemente de seu campo de atuação na sociedade, Severino (2006) se refere não à formação específica restrita a uma área, mas à formação humana. A formação apenas técnica tem se fortalecido devido aos poderosos avanços tecnológicos da informática. A força dessa formação é nutrida pelo capitalismo, sistema econômico em que cada indivíduo se preocupa com o desenvolvimento de si e não com o desenvolvimento social. Esses fatores interferem diretamente na formação universitária, levando a academia a formar indivíduos fortes em competir e fracos em pensar as questões sociais e científicas que os rodeiam. Percebemos, então, o primeiro grande impacto da falta de uma formação filosófica nas universidades. As instituições que deveriam se preocupar em formar sujeitos pensantes abrem espaço para uma formação apenas de caráter técnico e universalizada (Severino, 2006).

Não se trata de menosprezar a formação técnico-científica: ela é necessária, porém é preciso ir além das técnicas de transmissão e reprodução do conhecimento. É fundamental pensar, refletir e questionar os métodos e os meios de produção. Em sua prática, o educador atua como pessoa inteira e não apenas como técnico e, por isso, Röhr (2015) entende que é preciso, ao lado da formação profissional do educador, uma formação humana que o habilite a lidar com as questões da vida humana.

Em decorrência da dificuldade de escolher ou traduzir conteúdos de Filosofia a serem ensinados, Severino (2006) discorda da ideia de que a aprendizagem da Filosofia ocorre numa interação de transversalidade, em que os aprendizes irão despertar a capacidade de reflexão à medida que forem exercitando o conhecimento científico de outras áreas. Para o autor, a capacidade de reflexão dos sujeitos sem uma intervenção filosófica, na maioria das vezes, não é despertada. A atribuição de componentes curriculares de Filosofia no currículo de formação de professores, juntamente com componentes do campo técnico científico na grade curricular dos cursos de graduação, possibilita aos estudantes uma formação técnico-científica com a capacidade de refletir ao mesmo tempo sobre esta formação, sobre a técnica e sobre a ciência, sua natureza e sua construção (UFV.1.2. A filosofia trata da produção do conhecimento; UFV.1.3. A filosofia trata da evolução do conhecimento; UFV.1.4. A filosofia trata da aquisição do conhecimento).

A discussão em torno da natureza e da metodologia da ciência são reforçadas nas ementas (UNIFAL.1.4. A filosofia vinculada à metodologia das ciências trata do conhecimento científico; UNIFAL.1.5. A filosofia vinculada à metodologia das ciências trata do método científico; UNIFAL.1.6. A filosofia vinculada à metodologia das ciências se ocupa de diferentes tipos de pesquisa; UFV.2.3. A filosofia das ciências trata de metodologias modernas vinculadas às ciências e à epistemologia). As ementas ressaltam o vínculo da Filosofia à epistemologia. A Filosofia vincula-se à epistemologia no tratamento de metodologias modernas ligadas aos diferentes tipos de pesquisa. A epistemologia, área da Filosofia que se preocupa em descrever e verificar a natureza das teorias científicas conhecidas e a produção de novos conhecimentos científicos, apresentou-se nos componentes curriculares analisados vinculada à Filosofia em seu modo de questionar os métodos científicos empregados nas pesquisas científicas, como também as metodologias usadas para a produção do conhecimento científico. Questionar os métodos científicos é contribuir para o desenvolvimento das estruturas teóricas da ciência. As produções humanas, de modo geral, são ampliadas à medida que o ser humano questiona suas práticas. Um simples questionamento é, na verdade, central para a ampliação ou superação do já existente.

Nesta categoria, foi possível compreender que a Filosofia se torna uma reivindicação no que diz respeito às questões científicas, sociais e culturais, pois, sem as interrogações filosóficas, o sujeito tende a perpetuar o estabelecido e o vigente, e pouco compreende a si próprio. Inserir a Filosofia como componente curricular dos cursos de licenciatura em Química, além de apostar em uma formação humana do professor, tende a propagá-la. Essa formação humana perpassa o processo de autocompreensão de si a partir das tradições históricas que o constituem. O questionamento fomentado pela Filosofia é indispensável para ampliar ou superar os caminhos metodológicos trilhados pela ciência, possibilitando um afastamento do paradigma que coloca a ciência como imutável.

Na categoria a seguir, focalizamos a vinculação da Filosofia da Ciência à Epistemologia. Apresentaremos como isso repercute na Educação em Ciências e na formação de professores de Química.

\section{A Filosofia da Ciência na Formação de Professores de Química se Vincula à Epistemologia}

Outra categoria analítica percebida foi a que apresenta a ideia de que "A Filosofia da Ciência na Formação de Professores de Química se vincula à Epistemologia". Dessa categoria foi possível elaborarmos a seguinte síntese: Os componentes curriculares analisados mostraram que a Filosofia da Ciência aborda a sociedade; as relações sociais; a ética; a política e a educação na ciência, investigando os argumentos que os vinculam à Epistemologia. Assim, a Filosofia da Ciência se aprofunda no estudo das Ciências e da Epistemologia.

As unidades de significado UFV.2.1. e UFV.2.2. mostraram que a Filosofia da Ciência aborda as Ciências e a Epistemologia (UFV.2.1. A filosofia da ciência trata de epistemologia; UFV.2.2. A filosofia da ciência trata das ciências). A Filosofia da Ciência estuda as Ciências e a Epistemologia, 
visando a sustentação de argumentos que lhe permitam vinculálas às questões da sociedade, relações sociais, ética, política e educação (UFV.2.4. A filosofia da ciência trata de relações sociais vinculadas às ciências e à epistemologia; UFV.2.5. A filosofia da ciência trata do campo político vinculado às ciências e à epistemologia; UFV.2.6. A filosofia da ciência trata da ética vinculada às ciências e à epistemologia; UFV.2.7. A filosofia da ciência trata da sociedade vinculada às ciências e à epistemologia; UFV.2.8. A filosofia da ciência aborda a epistemologia e a educação). Assim, a partir da vinculação da Filosofia da Ciência com a Epistemologia, evidenciada pelas unidades de significado, podemos questionar: $\mathrm{O}$ que é Epistemologia? Qual é a relação da Epistemologia com a Filosofia da Ciência?

Com o objetivo de encontrarmos respostas que satisfaçam nossa interrogação, encontramos que

A palavra epistemologia deriva do grego, epistéme, ciência, verdade; logos, estudo, discurso, portanto, a epistemologia, no seu sentido etimológico, significa estudo ou discurso sobre a ciência ou sobre a verdade. Mas é um estudo essencialmente crítico dos princípios, das hipóteses e dos resultados das diversas ciências já constituídas e que se destina a determinar os fundamentos lógicos, o valor e o alcance objetivo delas (Ramos, 2008, p. 15).

Ramos (2008) afirma que a Epistemologia trata da gênese, do desenvolvimento, da articulação e da estruturação da ciência. A Epistemologia é entendida como o discurso sobre a ciência moderna. $\mathrm{O}$ autor define a Epistemologia como busca por um metaconhecimento científico, da qual emergem questões de como tal conhecimento acontece, qual o valor desse conhecimento e quais seus fundamentos lógicos. Todavia, essa tomada de consciência acontece sob uma perspectiva histórica. Para efetivar o discurso sobre a Ciência moderna é necessário estabelecê-la no tempo e na conjuntura das realizações humanas, que são historicamente determinadas.

Para Schulz (2014), a Epistemologia é:

O ramo da filosofia que estuda a natureza do conhecimento, seu escopo, fundamentos e validade; trata das teorias do conhecimento, das distinções entre acreditar e conhecer e justificar. A epistemologia científica preocupa-se em descrever e verificar a natureza do corpo de fatos e teorias científicas conhecidas (grau de certeza) e a produção de novos conhecimentos (ou seja, a investigação científica) (Schulz, 2014, p. 1265).

Dutra (2010) entende a Epistemologia como o termo mais utilizado para se referir à teoria do conhecimento. Ao partir das literaturas inglesa e francesa, o autor descreve a Epistemologia como, epistemology, em inglês, e épistémologie, em francês. No caso do francês, o termo era empregado com mais frequência para se referir à filosofia da ciência, mas, hoje, com a influência da literatura filosófica de língua inglesa, a tendência é, como em português, que o termo se refira a teoria do conhecimento (Dutra, 2010, p. 9).

Percebemos que a Epistemologia pode ser vista como teoria do conhecimento e como Filosofia da Ciência; porém, há uma diferenciação nas atribuições e no uso desses termos. A Epistemologia é mostrada como teoria do conhecimento quando se refere à área da Filosofia que aborda a familiaridade existente entre sujeito cognoscente e o objeto conhecido, e as questões levantadas por esta familiaridade. O dicionário de filosofia de Abbagnano (2012) apresenta a palavra "Epistemologia" - no inglês Epistemology; francês Épistémologie; alemão Epistemologie; italiano Epistemologia - como um termo de origem grega com duas acepções: i. como sinônimo de gnosiologia ou de teoria do conhecimento; ii. como sinônimo de Filosofia da Ciência. Ambos os significados estão proximamente interligados, "pois o problema do conhecimento, na filosofia moderna e contemporânea, se entrelaça (e às vezes se confunde) com o da ciência" (Abbagnano, 2012, p. 392). Em seguida, como complementação ao conceito de epistemologia, é indicado "ver Teoria do Conhecimento".

Em busca pelo significado apresentado para "Teoria do Conhecimento", verificamos em Abbagnano (2012) que a Epistemologia tem diferentes termos em línguas distintas. Em Inglês, utiliza-se o termo Epistemology, introduzido por J. F. Ferrier em 1854 e, raramente, gnoseology. Em Francês, o termo mais comumente utilizado é Gnoseologie e, raramente, Epistémologie. Em Italiano, utiliza-se Teoria della conoscenza, Gnoseologie, Epistemologia. Em Alemão, o termo Gnoseologie fez pouco sucesso, enquanto o termo Erkenntnistheorie, usado pelo kantiano Reinhold em 1789, teve aceitação geral.

A Epistemologia enquanto teoria do conhecimento se preocupa com o estudo da realidade das coisas, já a Epistemologia vinculada à Filosofia da Ciência se apresenta como crítica interna de uma ciência visando seu progresso e sua evolução. Esta acepção, por sua vez, está centralizada na própria ciência e, conforme aponta Ramos (2008), tem um caráter de teoria ou filosofia da ciência.

Em vez de nomear a Epistemologia de teoria do conhecimento, Nouvel (2013) a denomina de "filosofia do conhecimento". Esse autor, porém, não descarta a possibilidade de que haja um aparentamento entre teoria do conhecimento e filosofia do conhecimento. Contudo, denuncia um afastamento da filosofia das ciências em relação à epistemologia.

Diante disso, percebemos que as discussões no âmbito da Epistemologia são plurais no que diz respeito ao uso do termo. Como apresentamos até aqui, alguns autores a tratam como "Teoria do Conhecimento" ou "Filosofia do Conhecimento", 
outros a classificam como "Filosofia da Ciência" ou, ainda, "Filosofia da Ciência stricto sensu". Não temos a pretensão de decidir este impasse. Nossa pretensão esteve em perseguir a palavra epistemologia em diferentes acepções, até que percebêssemos sua vinculação à Filosofia da Ciência nas ementas dos componentes curriculares analisados. Percebemos que essas disputas conceituais não têm sido objeto de interesse desses componentes curriculares em cursos de Licenciatura em Química, uma vez que as unidades de significado apresentam a Epistemologia vinculada à Filosofia da Ciência.

Nessa busca, encontramos uma discussão em torno dos limites da Epistemologia apontado por Ramos (2008): discute-se se ela sozinha pode dar conta de analisar criticamente o conhecimento e o progresso das Ciências. $\mathrm{O}$ autor conclui que "a Epistemologia necessita da Hermenêutica para lhe auxiliar. Ao trabalharem juntas, a Epistemologia contribuirá para a explicação e a Hermenêutica contribuirá para a compreensão" (2008, p. 29-30).

Para Ramos, a "Hermenêutica é uma tentativa de compreender o que são as Ciências humanas e as suas conexões com a totalidade de nossa experiência no mundo" (2008, p. 29). Assim, sugere que a Epistemologia caminhe lado a lado da Hermenêutica. A Epistemologia explica e a Hermenêutica compreende. Bombassaro (1992) destaca que as proposições plausíveis de que a Epistemologia pode ser complementada pela Hermenêutica derivam dos filósofos Karl-Otto Apel e Richard Rorty. Reconhecendo a dificuldade em falar numa complementaridade entre Epistemologia e Hermenêutica, ambos os filósofos afirmam que através da Epistemologia só é possível dar conta dos elementos normativos e metodológicos do conhecimento. Ao analisar a visão de Rorty de que há uma necessidade de repartição de cultura entre Epistemologia e Hermenêutica, na qual a primeira ficaria com a parte cognitiva e a segunda se encarregaria do restante, Bombassaro (1992) interpreta que a Epistemologia deveria ocupar-se com a racionalidade e a Hermenêutica com a historicidade. A diferenciação entre Epistemologia e Hermenêutica está centrada na diferença entre explicação e compreensão; porém, Apel entende que essa distinção não pode ser sustentada, uma vez que a compreensão (Hermenêutica) sempre se faz presente na elaboração da explicação (Epistemologia). Assim, Bombassaro (1992) acrescenta que, quando se trata do conhecimento retratado em proposições e enunciados, a compreensão somente aparece quando ocorre a explicação.

Os debates em torno da mudança da Epistemologia para a Hermenêutica estão mais bem explicitados em Schulz (2014), e fogem ao escopo desta categoria de análise. Inspirados por esse autor, Sousa e Galiazzi (2017) trataram, especificamente, das contribuições da hermenêutica filosófica para a formação de professores de Química. Os autores destacam as limitações históricas, dialógicas, estéticas e de escrita na formação de professores de Química, categorias essas inspiradas na hermenêutica gadameriana.
A reivindicação de Sousa e Galiazzi (2017), específica para a formação de professores de Química, constitui uma alternativa às críticas colocadas por Ramos (2008). Este aponta que os conhecimentos científicos são muitas vezes recortados, fragmentados e descontextualizados por conta da sobrecarga de trabalho dos professores de Ciências. Desse modo, o conhecimento científico acaba sendo transmitido sem levar em consideração a historicidade e o processo de construção da ciência.

Para Schulz (2014), apesar de os professores de Ciências tradicionalmente se empenharem em apenas transmitir com precisão e exatidão o conhecimento científico canônico representado nos livros didáticos, questionar esse modo de ensinar Ciências é o começo para tornar o ensino humanizado. Esse autor destaca que não deve ser o objetivo do professor esperar que os alunos saibam apenas reproduzir tal conceito, tampouco esperar ouvir de seus alunos afirmações sobre crer naquilo que o livro apresenta, pois ensinar Ciências vai além da mera reprodução do conhecimento científico e transpassa a crença e as afirmações sobre conhecer ou não conceitos. Ensinar Ciências consiste em traçar caminhos que levem os alunos a trilharem pelo campo da compreensão por meio da explicação e vice versa. $\mathrm{O}$ ensino de Ciências não pode girar em torno de uma mudança de crenças ou dogmas, mas da compreensão.

Nessa passagem pelo debate em torno dos limites da Epistemologia protagonizados pela Hermenêutica, parece-nos restrita, nas ementas analisadas, a abordagem da Filosofia da Ciência na formação de professores de Química. Ao tratar apenas da perspectiva epistemológica na formação de professores de Química, há um reforço ao caráter a-histórico da ciência e seu ensino. A Hermenêutica traz para si a reivindicação das tradições históricas, possibilitando ao professor de Química compreender(-se) historicamente (n)a Química e perceber sua função de tradutor-intérprete dessas tradições nos contextos educativos (Sousa e Galiazzi, 2018).

Outras discussões possíveis, que se articulam à Filosofia da Ciência e que poderiam contribuir para a formação de professores de Química, envolvem a Filosofia da Química (Erduran, 2001; Lemes e Porto, 2013; Ribeiro, 2014) e a Filosofia da Ciência Hermenêutica (Ginev, 1997; Babich, 2016). Entretanto, não houve qualquer menção a essas subdisciplinas nos componentes curriculares investigados, contribuindo para uma elaboração ainda mais restrita dos questionamentos filosóficos à Ciência e à Química.

\section{A Filosofia da Educação na Formação de Professores de Química: entre Crises de Autoridade e Possibili- dades Educativas}

Sobre essa categoria, sintetizamos: Os componentes curriculares de Filosofia da Educação e Fundamentos da Educação dos cursos de formação de professores de Química em Minas Gerais mostraram que a Filosofia da Educação questiona a crise de autoridade na educação e a crise do conhecimento. A crise de autoridade na educação abre caminho para a crise 
do conhecimento, e esses problemas, juntos, desencadeiam uma crise na educação. A fim de compreendê-los, a Filosofia da Educação busca compreender o processo educativo desde os saberes necessários à prática docente até a organização do currículo escolar. Tanto a crise de autoridade quanto a crise do conhecimento são consequências do processo de ensino vivenciado pelos alunos e professores.

Iniciaremos com uma incursão por alguns momentos históricos pelos quais a Filosofia e a Educação constituíram uma Filosofia da Educação. Faremos essa incursão de modo a compreendermos como essa Filosofia da Educação começou a fazer parte de cursos de formação de professores e para articularmos as ideias que estão apresentadas na síntese desta seção.

A história da Filosofia nos coloca que a Educação sempre foi um seus objetos de reflexão. Essa relação nasce com a Filosofia, enquanto preocupação com a formação do homem. A expressão paideia está vinculada à história grega, com a qual se buscou a formação de um elevado tipo de Homem. Historicamente, filósofos que se dedicaram à educação a compreendem como processo de formação. Por isso, eles podem ser considerados iniciadores do discurso sobre educação (Tomazetti, 2003).

Tomazetti (2003) argumenta que a ideia do filósofo preceptor antecedeu a escola primária, instituída no século XVIII pela Revolução Francesa. No século XVIII, surge a discussão da Pedagogia como disciplina científica, sua colocação como ciência e sua relação com a Filosofia. A Pedagogia como uma nova ciência da educação apareceu na Alemanha, em torno de 1770 (Hermann, 2015). Com o processo de escolarização, o pensamento sobre educação passou a envolver, além de uma reflexão sobre o homem, também sobre a escolarização. $\mathrm{Na}$ Alemanha, a criação da disciplina Pedagogia, na Universidade Halle/Saale, em 1779, marca o começo da separação institucional entre a Pedagogia e a Filosofia (Hermann, 2015). Na França, a filosofia da Educação esteve associada à Pedagogia geral até o início do século XX (Tomazetti, 2003).

Essa separação não só marca o início de um processo de emancipação, mas também, nas próximas décadas, assinala a crescente retirada da filosofia da tematização de questões educativas. Com esse recuo, a educação tem cada vez mais seu campo definido pelas ciências e pela crescente penetração dos procedimentos considerados próprios da ciência. Isso acarretou o predomínio do cientificismo na pedagogia, a ponto de causar estranheza o fato de uma investigação que não fosse empírica (Hermann, 2015, p. 220).

Podemos interpretar este cientificismo a partir do que Schulz (2014) entende pela palavra. Para ele, o cientificismo se trata de uma visão de mundo excludente e hegemônica, que afirma que cada questão de visão de mundo pode ser mais bem respondida exclusivamente pelos métodos da ciência, e que não há necessidade de outros recursos além dela. Isso é corroborado pelo contexto histórico em que se estabelece o modelo de racionalidade que regula a ciência moderna.

Esse modelo se constituiu a partir do século XVI e subsequentes, sob o domínio das ciências naturais, sendo estendido às ciências sociais a partir do século XIX. Estabelece-se, então, como um modelo totalitário, ao negar o caráter racional daquelas formas de conhecimento que não se pautarem por seus fundamentos epistemológicos e metodológicos (Santos, 2010). Há uma crise nesse paradigma dominante, resultado de uma pluralidade de condições. Como exemplo, Santos destaca a identificação dos limites e das insuficiências estruturais deste paradigma, resultantes do avanço do conhecimento por ele mesmo proporcionado, deixando expostas as fragilidades de seus pilares. Outra condição para a crise desse paradigma está na interferência estrutural do sujeito no objeto observado. Santos (2010) exemplifica ainda o abalo do rigor da medição, ou seja, o rigor da Matemática posto à prova pela mecânica quântica. Em certas circunstâncias, há a impossibilidade de encontrar em um sistema formal a prova de sua consistência, mesmo ao seguir exatamente as regras da lógica matemática. Essas são algumas das condições teóricas colocadas pelo autor para a crise da ciência moderna e do conhecimento por ela proporcionado que nos remetem à unidade de significado UFOP.1.3 (UFOP.1.3. Os estudos filosóficos sobre educação envolvem a crise do conhecimento). Uma Filosofia da Educação na formação de professores de Química que apresente as condições dessa crise do paradigma dominante, que questione o processo de produção do conhecimento, sua aquisição e sua evolução, estará articulada com a ampliação do conhecimento para além do hegemônico.

Hermann (2015) mostra que no currículo dos cursos de formação de professores há uma crescente fragmentação do objeto pedagógico, tanto que acabamos por confundir educação com qualificação profissional utilitarista. Com o efetivo recuo da Filosofia pelo avanço da Pedagogia no século XX, a primeira se autonomiza, e acaba por imitar as Ciências Naturais, focalizando a alta especialização, desvencilhando-se da tradição e distanciando-se de pensar a educação.

A partir do corpus de análise, mostra-se que a Filosofia da Educação tratada em cursos de Licenciatura em Química em Minas Gerais se preocupa em estudar a crise de autoridade na educação (UFOP.1.2. Os estudos filosóficos sobre educação envolvem a crise de autoridade e a educação). Evidencia-se que a crise de autoridade na educação juntamente com a crise do conhecimento levam a uma crise na educação. Assim, mostra-se como potencialidade dessa categoria entendermos o que vem a ser essa autoridade da educação, provocada pela crise do conhecimento que desemboca numa crise da educação.

Winch e Gingell (2007) apresentam o conceito de autoridade dividindo-o em dois tipos: estar com a autoridade e ser uma autoridade. No caso do primeiro, a autoridade corresponde a ter o direito e estar autorizado a fazer com que as vontades próprias 
sejam atendidas. No segundo, trata-se de possuir conhecimento no qual se pode confiar. Na tradição educacional, os educadores são considerados autoridades em ambos os sentidos. Entretanto, recentemente, a autoridade dos professores, em geral, passou a ser questionada. Este questionar partiu, principalmente, de educadores progressistas que destacam os danos psicológicos e pedagógicos em função de uma imposição ostensiva das vontades de uma pessoa sobre a outra. Eles defendem, assim, a mudança do papel dos professores para um modelo não autoritário, para o professor como um "facilitador da aprendizagem".

A rejeição à autoridade na educação tem raízes em JeanJacques Rousseau (1712-1778), que compreendia que a frustração, a oposição e o impedimento recorrentes à vontade do aluno teriam efeitos psicológicos danosos. Por outro lado, Rousseau não descartava a autoridade no processo educativo, pois acreditava que o poder da autoridade do professor deveria ser exercido sem o conhecimento da criança (Winch e Gingell, 2007).

Há dois argumentos em torno da negação da autoridade na educação: o primeiro vincula o ensino com autoridade à doutrinação; o segundo admite que a autoridade viola a autonomia do aluno. De acordo com o primeiro argumento, não há possibilidade de questionamento das informações, já que elas se apresentam como verdadeiras e irrefutáveis. A violação da autonomia do aluno pela autoridade provoca a desarticulação do objetivo educacional de possibilitar aos educandos a adoção de valores que não são necessariamente aprovados pela sociedade. Em uma aposta na autonomia como objetivo educacional desejável, uma sociedade que se propõe a fixar valores a serem restritivamente ensinados estaria, ela mesma, sendo autoritária (Winch e Gingell, 2007).

Assim, atualmente, compreendem-se os impactos de uma postura autoritária nos contextos educativos, ao mesmo tempo que se reivindica a autoridade do professor dentro deles. Entretanto, busca-se menos o estar com autoridade-impositiva e dominadora - e mais o ser uma autoridade - ser reconhecido como alguém em cujo conhecimento se pode confiar.

Desde o Iluminismo, a noção de autoridade foi tratada com suspeita, pois a autoridade é, muitas vezes, arbitrária e sancionada apenas por poderes institucionais, sem ser legitimada pela razão. Os pensadores do Iluminismo questionaram essa autoridade arbitrária, especialmente no domínio do político. Eles rejeitavam o aprendizado e a erudição do passado, alegando que ele não tinha uma justificativa racional. Gadamer entende que nem toda autoridade genuína deva ser sancionada pela razão. Esse filósofo entende que um bom professor tem e é uma autoridade não simplesmente em virtude do poder investido nele pelo estado. Um bom professor, com a capacidade de atrair os alunos para as conversas da cultura, carrega sua própria autoridade (Lawn e Keane, 2011). Isso porque esse professor tem sua autoridade legitimada pela tradição histórica, colocando-se em seu tempo histórico como intérprete da tradição (Sousa e Galiazzi, 2018).
Diante disso, compreender acerca da autoridade como categoria à qual se dedica a Filosofia da Educação na formação de professores de Química é um indicativo de sua exigência nesta formação. A Filosofia da Educação se apresenta, portanto, como um exercício à reflexão e ao questionamento da prática educativa do professor de Química. Isso está bem evidenciado em algumas unidades de significado (UFLA.1.1. Estudo de correntes filosóficas que possibilitem a compreensão do processo educativo; UFOP.1.4. Os estudos filosóficos sobre educação envolvem o processo de organização do currículo escolar; UFOP.1.5. Os estudos filosóficos sobre educação envolvem os saberes docentes necessários à prática docente), que mostram que a Filosofia da Educação busca entender o processo educativo desde os saberes necessários à prática docente até a organização do currículo escolar.

Ao buscarmos compreender a Filosofia da Educação na formação de professores de Química e sua aproximação com a Educação em Ciências e, por consequência, com a Educação Química, podemos iniciar pela metáfora utilizada por Schulz (2014) para caracterizá-la. O autor utiliza a metáfora de Jano para apresentar a Filosofia da Educação, cuja dupla face olha tanto para a filosofia (teoria) quanto para as implicações educacionais (prática). A aparente incapacidade de promover mudanças maiores e mais duradouras a partir dos diferentes "movimentos de reformas" no ensino de Ciências, indica Schulz (2014), pode sugerir a necessidade de uma avaliação dos problemas mais concentrada nos aspectos filosófico-educacionais. Para o autor, há uma insuficiência filo-educacional, cuja superação poderia contemplar os motivos pelos quais as reformas curriculares são vulneráveis aos caprichos políticos de vários grupos. Por isso, a Filosofia da Educação em Ciências proposta por Schulz (2014) poderia ajudar não apenas a definir uma identidade para a Educação em Ciências, mas também uma identidade para o profissional da sala de aula.

Schulz (2014) apresenta algumas abordagens dos estudos no campo da Filosofia da Educação: i. estudar filósofos e suas visões de educação; ii. estudar pensadores educacionais e suas posições filosóficas; iii. estudar sub-ramos da Filosofia e sua relevância para a educação; iv. estudar "escolas de pensamento" em educação; v. estudar as questões filosóficas de preocupação central. Essas abordagens perpassam as possibilidades de vinculação filosófica de professores para exercerem sua prática docente e estarem aptos a questioná-la, quando necessário, buscando outras vinculações. Contemplam ainda uma percepção ampla da educação e de sua construção histórica, compreendendo sua própria formação na contemporaneidade.

Um aluno de licenciatura em Química deve se perguntar sobre a importância da Filosofia da Educação em sua preparação para o magistério. Mas a Química, como qualquer outra área do conhecimento, apresenta processos, experiências, resultados e descobertas que, no limite, pressupõem que novas 
relações podem ser estabelecidas entre os homens e os materiais a sua volta. Quando chega nesse ponto, esses processos devem ser questionados à luz da ética, sendo necessário, por extensão, que transcendam os limites epistemológicos e sejam colocados num discurso ontológico ou, ainda mais próximo de nós, existencial, porque o que está, de fato, em discussão é a vida do homem, mas não de um homem qualquer e sim de um homem histórico, cuja missão é mudar o mundo para melhor. Estudos de Química que não considerarem esses aspectos esvaziam-se na penumbra dos laboratórios (Cardoso, 2004, p. 85).

Essas abordagens estão comprometidas em estudar a construção social, política e ética, à medida que são colocados em evidência diferentes modelos filosóficos do que se almeja para uma sociedade. Isso repercute no questionamento de que pessoas os professores de Química pretendem formar a partir de suas ações educativas. Isso reivindica além de uma educação química com parâmetros epistemológicos bem definidos. Trata-se de questionar ontologicamente a si, como sujeito histórico e profissional da educação e, a partir da busca pela autocompreensão, delinear uma paisagem daquilo que se pretende filosoficamente para a sociedade.

\section{Considerações Finais}

Coerentes com nosso questionamento inicial, dedicamo-nos, especialmente, àqueles cursos com componentes curriculares com alguma vinculação à Filosofia, à Filosofia da Ciência ou a Filosofia da Educação. Outros cursos ainda estão por encontrar essa necessidade, e esperamos que este artigo contribua para esse encontro. Nosso questionamento inicial foi: $O$ que é isto que se mostra: a Filosofia na formação de professores de Química em Minas Gerais?, ao qual respondemos a seguir, como argumento central deste artigo.

As abordagens filosóficas na formação de professores de Química de Minas Gerais possuem sua centralidade na Filosofia da Educação em seu quantitativo, o que nos parece uma escolha acertada para cursos de formação de professores. Pouco se aposta na Filosofia como componente curricular mais geral e na Filosofia da Ciência nos cursos de formação de professores de Química analisados.

No âmbito qualitativo, as três categorias descritas e interpretadas se articulam ao tratarem de epistemologia, de metodologia científica, de crise do conhecimento e de crise na educação. Assim, a Filosofia que se mostra nas ementas na formação de professores de Química em Minas Gerais se dedica a questionar o método científico fundamentado na racionalidade técnica da ciência moderna. Questiona ainda a vinculação epistemológica desse paradigma totalitário na formação de professores de Química. Parece-nos, portanto, que a Filosofia na formação de professores de Química em Minas Gerais mais do que provoca a reflexão: ela denuncia. A denúncia é um alerta para a não vinculação de professores de Química a este paradigma.

Ao longo do texto, apresentamos elementos para um afastamento desse paradigma. Reivindicamos o questionamento filosófico das práticas educativas, dos currículos vigentes e estabelecidos na escola, da ciência propagada nos conteúdos de ensino selecionados, da postura educativa com os estudantes e outros profissionais da educação e da necessidade de abertura a outras perspectivas filosóficas na formação de professores de Química. Além disso, assumimos o chamamento da história à centralidade da educação filosófica de professores de Química, entendendo-a mais do que uma ferramenta para contextualizar a aula de Química, mas para colocar o professor de Química como sujeito histórico propagador das tradições da Química, legitimado por seu tempo histórico.

Por último, reforçamos os argumentos de Schulz apresentados ao longo deste texto sobre a importância de uma Filosofia da Educação específica. Schulz tem defendido uma Filosofia da Educação em Ciências, integrando Filosofia, Filosofia da Ciência e Filosofia da Educação, como mostrado, e servindo de base para os eixos analíticos. Se é possível assim pensar, finalizamos o texto com uma pergunta. Não seria uma exigência caminhar para uma integração dos três eixos aqui analisados - Filosofia, Filosofia da Educação e Filosofia da Ciência -, valorizando a implementação da Filosofia da Educação em Ciências nos cursos de licenciatura?

Isso também nos leva a pensar que a Química, como uma ciência estabelecida, possui suas tradição e linguagem consolidadas nos cursos de formação de professores. Essa tradição, entretanto, está ausente das ementas analisadas. Se a Filosofia da Ciência aparece pouco, a Filosofia da Química não aparece em nenhuma ementa sequer de todas as analisadas, embora seja campo teórico consolidado. A partir do argumento de Schulz sobre a criação da Filosofia da Educação em Ciências, não se poderia também pensar em uma Filosofia da Educação Química? Esta questionaria, por exemplo, a Educação Química como uma ciência reduzida a seus métodos, que analise os modos de produção do conhecimento químico em suas tradições (Filosofia da Química/História da Química). Isso contribuiria com outros modos de analisar, compreender e ensinar o conhecimento químico, como é um deles a Hermenêutica. Uma Filosofia da Educação Química culminaria, então, com o questionamento dos modos de ser professor de Química na tradução e na interpretação do conhecimento de Química em aula.

\section{Notas}

${ }^{1}$ Para Sjöström (2007), o objetivismo representa a visão de que os fatos científicos são independentes do contexto no qual são observados.

${ }^{2}$ Chassot (1995) aponta o ensino de Química com termo "a-histórico" para tratar o ensino médio como contrário à história, anistórico, alheio à história. 
${ }^{3} \mathrm{O}$ software Qgis é um sistema de informação geográfica livre e aberto que permite a visualização, edição e análise de dados georreferenciados (Qgis, 2019).

${ }^{4}$ Codificamos as unidades de significados a partir da sigla da universidade federal em que o componente curricular ocorre, seguida do número do componente curricular (1, para a primeira encontrada, 2, para a segunda na mesma universidade e assim por diante) e, por fim, o número da unidade de significado encontrada na ementa. Ficamos, portanto com o código "UFX.1.1" para indicar que a unidade de significado 1 está na ementa do componente curricular 1 da UFX, sendo UFX uma universidade federal genérica.

${ }^{5}$ Ariza et al. (2015) explicitam pormenores de como é realizado o processo desde a unitarização até a escrita do parágrafo-síntese. Os autores apresentam exemplos concretos e com riqueza de detalhes acerca da reescrita das unidades de significado, das aproximações delas para constituição de frases síntese, até a elaboração de parágrafos que as articulem. O mesmo procedimento foi realizado na Análise Textual Discursiva aqui apresentada.

${ }^{6}$ Embora com nomenclaturas distintas, Filosofia da Educação em Ciências para Schulz (2014) e Filosofia do Ensino de Ciências para Gois (2017), entendemos que a Educação em Ciências e o Ensino de Ciências ocorrem concomitantemente, como ressaltado por Sousa e Galiazzi (2017). Assim, parece-nos que a nomenclatura atribuída à região de fronteira é um apenas detalhe quando comparamos com a reivindicação emergente desses autores por uma articulação da Filosofia com a Educação em Ciências ou com o Ensino de Ciências.

${ }^{7}$ As universidades federais situadas em Minas Gerais são: Universidade Federal de Alfenas (UNIFAL), Universidade Federal de Itajubá (UNIFEI), Universidade Federal de Juiz de Fora (UFJF), Universidade Federal de Lavras (UFLA), Universidade Federal de Minas Gerais (UFMG), Universidade Federal de Ouro Preto (UFOP), Universidade Federal de São João del-Rei (UFSJ), Universidade Federal do Triângulo Mineiro (UFTM), Universidade Federal de Uberlândia (UFU), Universidade Federal de Viçosa (UFV), Universidade Federal dos Vales do Jequitinhonha e Mucuri (UFVJM).

${ }^{8}$ Algumas coordenações de curso prontamente disponibilizaram os PPC's ou as ementas de nosso interesse quando contatadas via correio eletrônico.

\section{Referências}

ABbagnano, N. Dicionário de filosofia. $6^{\text {a }}$ ed. São Paulo: Editora WMF Martins Fontes, 2012.

ARIZA, L. G. A.; DIAS, V. M. T.; SOUSA, R. S.; NUNES, B. R.; GALIAZZI, M. C. e SCHMIDT, E. B. Relaciones entre el análisis textual discursivo y el software ATLAS.ti en interacciones dialógicas. Campo Abierto. Revista de Educación, v. 34, n. 2, p. 105-124, 2015.

$\mathrm{BABICH}, \mathrm{B}$. E. Hermeneutic philosophy of science: interpreting nature, reading laboratory science. In: KEANE, N. e LAWN, C. (Eds.). The
Blackwell companion to hermeneutics. Chichester: John Wiley \& Sons, 2016, p. 492-504.

BERTICELLI, I. A. Educação em perspectivas epistêmicas pósmodernas. Chapecó: Argos, 2010.

BOMBASSARO, L. C. As fronteiras da epistemologia: como se produz o conhecimento. $2^{\text {a }}$ ed. Petrópolis: Vozes, 1992.

CARDOSO, J. B. Formação de professores: transformação e reprodução. Poiésis, v. 2, n. 2, p. 73-91, 2004.

CHASSOT, A. Para que(m) é útil o ensino? Alternativas para um ensino (de química) mais crítico. Canoas: Ed. Ulbra, 1995.

DUTRA, L. H. A. Introdução à epistemologia. São Paulo: Editora UNESP, 2010.

ERDURAN, S. Philosophy of chemistry: an emerging field with implications for chemistry education. Science \& Education, v. 10, n. 6, p. 581-593, 2001.

FLICKINGER, H.-G. A caminho de uma pedagogia hermenêutica. Campinas: Autores Associados, 2010.

GALLO, S. Filosofia da educação no Brasil do século XX: da crítica ao conceito. EccoS Revista Científica, v. 9, n. 2, p. 261-284, 2007.

GINEV, D. A passage to the hermeneutic philosophy of science. Amsterdam: Rodopi, 1997.

GOIS, J. Filosofia do ensino de ciências: significação e representações químicas. Ijuí: Ed. Unijuí, 2017.

HERMANN, N. Pensar arriscado: a relação entre filosofia e educação. Educação e Pesquisa, v. 41, n. 1, p. 217-228, 2015.

LAWN, C. e KEANE, N. The Gadamer dictionary. Londres: A\&C Black, 2011.

LEMES, A. F. G. e PORTO, P. A. Introdução à filosofia da química: uma revisão bibliográfica das questões mais discutidas na área e sua importância para o ensino de química. Revista Brasileira de Pesquisa em Educação em Ciências, v. 13, n. 3, p. 121-147, 2013.

MARTINS, J. e BICUDO, M. A. V. Estudos sobre existencialismo, fenomenologia e educação. $2^{\mathrm{a}}$ ed. São Paulo: Centauro, 2006.

MORAES, R. e GALIAZZI, M. C. Análise textual discursiva. $3^{\mathrm{a}}$ ed. revisada e ampliada. Ijuí: Unijuí, 2016.

NOUVEL, P. Filosofia das ciências. Campinas: Papirus, 2013.

QGIS. Disponível em https://www.qgis.org/pt_BR/site/index.html, acessada em Junho 2019.

RAMOS, M. G. Epistemologia e ensino de ciências: compreensões e perspectivas. In: MORAES, R. (Org.). Construtivismo e ensino de ciências: reflexões epistemológicas e metodológicas. $3^{\mathrm{a}}$ ed. Porto Alegre: EDIPUCRS, 2008, p. 13-35.

RIBEIRO, M. A. P. Integração da filosofia da química no currículo de formação inicial de professores: contributos para uma filosofia do ensino. Tese (Doutorado em Educação). Universidade de Lisboa, Lisboa, 2014.

RÖHR, F. Formação filosófica do educador. Itinerários de Filosofia da Educação, v. 13, p. 106-116, 2015.

SANTOS, B. S. Um discurso sobre as ciências. $7^{\text {a }}$ ed. São Paulo: Cortez, 2010.

SCHULZ, R. M. On the way to a philosophy of science education. Thesis (Philosophy Doctorate). Simon Fraser University, Burnaby, 2010 . 
Rethinking science education: philosophical perspectives. Charlotte: Information Age Publishing, 2014.

SEVERINO, A. J. A Formação filosófica na universidade. In: MAAMARI, A. M.; BAIRROS, A. T. C. e WEBER, J. F. (Orgs.). Filosofia na universidade. Ijuí: Ed. Unijuí, 2006, p. 91-106.

SJÖSTRÖM, J. The discourse of chemistry (and beyond). HYLE International Journal for Philosophy of Chemistry, v. 13, n. 2, p. 83-97, 2007.

SOUSA, R. S. e GALIAZZI, M. C. A tradição de linguagem em Gadamer e o professor de química como tradutor-intérprete. ACTIO: Docência em Ciências, v. 3, n. 1, p. 268-285, 2018.

$\mathrm{e}$ Compreensões acerca da hermenêutica na análise textual discursiva - marcas teórico-metodológicas à investigação. Contexto \& Educação, v. 31, n. 100, p. 33-55, 2016. e Traços da hermenêutica filosófica na educação em ciências: possibilidades à educação química. Alexandria: Revista de Educação em Ciência e Tecnologia, v. 10, n. 2, p. 279-304, 2017. e SCHMIDT, E. B. Interpretações fenomenológicas e hermenêuticas a partir da análise textual discursiva: a compreensão em pesquisas na educação em ciências. Revista Pesquisa Qualitativa, v. 4, n. 6, p. 311-333, 2016.

TOMAZETTI, E. M. Filosofia da educação: um estudo sobre a história da disciplina no Brasil. Ijuí: Ed. Unijuí, 2003.

WINCH, C. e GINGELL, J. Dicionário de filosofia da educação. São Paulo: Contexto, 2007. 